\title{
Commodity Taxation and International Trade in Imperfect Markets ${ }^{1}$
}

\author{
Andreas Haufler \\ University of Göttingen and CESifo \\ Guttorm Schjelderup \\ Norwegian School of Economics and Business Administration and CESifo \\ Frank Stähler \\ University of Kiel
}

October 2000

\begin{abstract}
${ }^{1}$ Paper presented at the 56th Congress of the International Institute of Public Finance (IIPF) in Seville, at the Annual Congress of the German Economic Association in Berlin, and at seminars in Freiburg and Kiel. We are indebted to Thorsten BayindirUpmann, Michael Pflüger and especially Agnar Sandmo for helpful comments. This paper was started while Schjelderup and Stähler visited the University of Konstanz and continued while Haufler and Stähler were at the Norwegian School of Economics and Business Administration in Bergen. We wish to thank both institutions for their hospitality. Financial support from the Center of Finance and Econometrics (CoFE) at the University of Konstanz and the Norwegian Research Council, grant number 137114/510, is gratefully acknowledged.
\end{abstract}




\begin{abstract}
This paper studies non-cooperative commodity taxation in a trade model with imperfect competition and trade costs. Nationally optimal tax policy simultaneously tries to correct the domestic distortion from imperfect competition and to shift rents to the home country. Importantly, this trade-off depends qualitatively on the international commodity tax regime in operation. For low levels of trade costs, we show that production-based commodity taxes dominate from a global welfare perspective, but this ranking is reversed in favor of consumption-based taxation when trade costs become sufficiently high.
\end{abstract}

Keywords: commodity taxation, imperfect competition, strategic trade policy JEL-Classification: F12, H20. 


\section{Introduction}

In 1999, revenues from taxes on goods and services represented 12.6 and 8 percent of GDP in the EU and the OECD, respectively, making indirect taxes the most important source of tax revenue in the EU and the third most important source in the OECD. ${ }^{1}$ Among the various indirect taxes used, the value-added tax (VAT) is by far the most important. While only nine countries levied this tax in the 1960s, this number has meanwhile increased to more than one hundred (Cnossen, 1998). The VAT is used by all OECD countries, except the United States, and it has also become increasingly popular in developing countries. It is now employed by all Latin American countries, as well as many African and ex-communist economies of Eastern Europe. The VAT is also proposed as an alternative tax in the United States, since the existing system of retail sales taxes has been repeatedly criticized as an inefficient way of raising tax revenue (Mikesell, 1997). ${ }^{2}$

The success of the VAT can be attributed to at least two factors. First, since VAT is paid at each stage of production, it is very difficult to avoid. Second, the increased mobility of national income tax bases - capital income, in particular - has led many countries to increase their reliance on commodity taxes. The increased dependence on VAT and the deepening of international economic integration make it important, however, to study the international repercussions of national commodity taxes. In particular, a core policy issue is whether traded commodities should be taxed in the country of consumption (destination principle), or in the country of production (origin principle). This question has been debated in the European Union since its founding days, and it has re-gained a prominent place in policy discussions due to the abolition of border controls in the internal market (see Keen and Smith, 1996). Its relevance is, however, not confined to the EU but applies equally to other integrating nations, such as the Commonwealth of Independent States, or to federal economies with some subnational tax autonomy (e.g. Canada, Brazil, India and the U.S.).

\footnotetext{
${ }^{1}$ In the OECD, the largest source of tax revenue is derived from personal income (9.3\% of GDP), followed by social security taxes (9.3\%) and taxes on goods and services (8\%). See OECD (1999).

${ }^{2}$ Rates of sales taxation in the United States are, on average, below 8 percent, compared with a total OECD average for the VAT of almost 20 percent. As a consequence, revenue from consumption taxes are much lower in the US than in the rest of the OECD. See OECD (1999).
} 
From a theoretical perspective, the issue of how commodity taxes should be levied is closely related to the theory of economic integration and international trade policy. If economic integration is perfect in the sense that goods and consumers can move without costs across borders, a jurisdiction that sets its tax rate above that of other countries will find that no tax revenue can be raised. The literature on international commodity taxation has shown that production taxes - but not consumption taxes - give rise to tax base externalities and will generally cause governments to set tax rates too low in the non-cooperative Nash equilibrium (Mintz and Tulkens, 1986; Kanbur and Keen, 1993). In the presence of additional terms of trade effects strategic motives also appear under the destination principle (Lockwood, 1993), but this is of concern only if countries are large in the world economy. Hence the possibility to avoid mutually destructive beggar-thy-neighbor policies has been one of the most important arguments for consumption-based commodity taxation. ${ }^{3}$

The importance of international fiscal externalities caused by national commodity taxes suggests that public finance and trade theorists could benefit from working jointly on these issues. Nevertheless, there has been remarkably little interchange between the two fields of research. One important dividing line between international public finance on the one hand and modern international trade theory on the other seems to be that the literature on international taxation and tax competition has remained largely within the competitive paradigm while most of the modern trade literature focuses on imperfectly competitive product markets.

In the 'new' international trade literature, it is well established that the presence of imperfect competition offers an increased range for strategic trade policies, even for small countries. A variety of different scenarios has been analyzed, leading to very different conclusions as to whether trade should be taxed or subsidized from the perspective of a home government maximizing national welfare (e.g. Brander and Spencer, 1984, 1985; Eaton and Grossman, 1986). In almost all instances, however, the focus has been on trade taxes, which allow governments to discriminate between the tax treatment of foreigners and domestic agents. But one of the core implications

\footnotetext{
${ }^{3}$ The other core argument is that the destination principle, but not the origin principle, is compatible with production efficiency when tax rates differ across countries and firms behave competitively. A detailed recent survey of these issues is given in Lockwood (1998).
} 
of market integration has been precisely that such discriminatory trade taxes are largely abolished, at least among industrialized countries.

One of the few contributions to the literature on international commodity taxation that departs from the assumption of competitive product markets is a recent paper by Keen and Lahiri (1998). ${ }^{4}$ Using a duopoly model with integrated national markets they argue for both cooperative and non-cooperative tax policies that imperfect competition is likely to reverse the general presumption in favor of the destination principle that emerges from models with perfectly competitive markets. One major finding in their paper is that in a symmetric Cournot duopoly with non-cooperative tax setting the origin principle achieves the first best, whereas the same is not true under the destination principle. The trade model of Keen and Lahiri is not able, however, to capture the well-established empirical fact of intra-industry trade. Furthermore, their analytical set-up does not allow an investigation of trade liberalization, which has been a core issue in the recent international trade literature.

In the present paper we bring together public finance and trade theory and analyze the above-mentioned choice between destination- and origin-based commodity taxes in a framework of non-cooperative tax setting under imperfect competition. In comparison to Keen and Lahiri (1998), we introduce additional model elements that are characteristic for the 'new' trade theory. First, we account for the fact that trade among industrialized countries is predominantly of the intra-industry type, so that the trade model used should be able to explain this phenomenon. Second, and more important for our results, the existence of trade costs is an integral element of our analysis. A trade model which meets these requirements and simultaneously allows for strategic interactions between firms is the 'reciprocal dumping' model of Brander and Krugman (1983). In this model two-way trade in homogeneous products arises from the assumption that national markets are segmented rather than integrated. Furthermore, trade costs play a dual role as they affect duopolistic competition between firms and also add a real resource cost to international transactions. ${ }^{5}$

\footnotetext{
${ }^{4}$ Imperfect competition has also been introduced in some recent analyses of environmental tax competition (Markusen, Morey and Olewiler, 1995; Rauscher, 1995; Hoel, 1997) and capital tax competition (e.g. Janeba, 1998; Osmundsen, Hagen and Schjelderup, 1998; Haufler and Wooton, 1999). For an overview, see Wilson (1999).

${ }^{5} \mathrm{An}$ alternative framework which accounts for intra-industry trade is a model with heteroge-
} 
The importance of trade costs has been emphasized in much of the recent international trade literature. From a theoretical perspective, trade costs allow to incorporate a 'home bias' in international trade patterns (Krugman, 1980), and they can also be used to explain successive phases of diverging and converging developments between industrial cores and the periphery (Krugman and Venables, 1995). Summarizing the empirical evidence, Norman (1998, p. 62) concludes:

\footnotetext{
"Even allowing for imperfect competition, studies show that the pattern of market shares seen in European markets can be made consistent with profit maximizing firms only if the sum of natural and artificial barriers to trade is equivalent to tariffs of 30-60 percent, depending on the product."
}

Our main finding is that the existence of trade costs in a model with segmented markets leads to conclusions that differ significantly from those derived in previous work. With imperfect competition and non-cooperative behavior by governments, tax policy is set to achieve two goals. The first is to correct the market failure that stems from oligopolistic competition, while the second pertains to the use of the tax system as a way to shift rents to the domestic economy. Whether nationally optimal taxation is consistent with global welfare maximization depends on both the tax principle in operation and the level of economic integration. In the absence of trade costs, we confirm the result of Keen and Lahiri (1998, Proposition 6) that the outcome of non-cooperative tax setting under the origin principle Pareto dominates the Nash equilibrium allocation under the destination principle. However, we also show that the efficiency case for the destination principle reappears when trade costs are introduced. Hence, in the presence of trade costs, imperfect competition does not generally lead to an argument in favor of production-based commodity taxation. In the remainder of the paper we proceed as follows. Section 2 describes the basic model and analyzes optimal tax policy with destination-based commodity taxes.

neous goods and monopolistic competition, as first used in Krugman (1979). This model, however, has no strategic interaction between firms and the existence of differentiated products makes it difficult to compare its results with those of Keen and Lahiri (1998), where products are homogeneous. 
Section 3 performs the same analysis for origin-based commodity taxation and compares the level of tax rates under the two regimes. Section 4 compares global welfare under the destination and origin principles when taxes are set non-cooperatively. Section 5 concludes and discusses some possible extensions of our analysis.

\section{The model with consumption taxes}

The basic structure of our model is adopted from the reciprocal dumping model of Brander (1981) and Brander and Krugman (1983). We consider two countries, home and foreign, which are identical in all respects. We thus explain the basic setup of the model from the viewpoint of the domestic country only; all foreign variables - denoted by an asterisk - are derived analogously. There are two goods, $X$ and $Z$, where goods produced in different countries are perfect substitutes. Good $X$ is produced in an oligopolistic industry whereas the numeraire good $Z$ is produced in a perfectly competitive sector. The preferences of the representative consumer are given by the quasi-linear utility function

$$
U(X, Z)=u(X)+Z
$$

where $u(X)$ is three times differentiable with $u^{\prime}>0$ and $u^{\prime \prime}<0$.

The consumer is endowed with a fixed amount of labor $(L)$. Labor is the only factor of production and is intersectorally mobile, but internationally immobile. Labor units are measured such that one unit of labor produces one unit of commodity $Z$, implying that the wage rate is equal to unity. In addition to wage income the representative consumer receives all profits (П) earned by the domestic firm in the oligopolistic market. Furthermore, following a standard procedure in the trade literature we assume that tax revenue $T$ is returned to the consumer as a lump sum. Thus, the social valuation of one dollar of tax revenues is equal to the marginal utility of the numeraire good $Z$. Denoting the consumer price of good $X$ by $p$, the consumer's budget constraint is given by

$$
L+\Pi+T=p X+Z \text {. }
$$

Utility maximization subject to the budget constraint (2) yields the demand function for good $X$ which, under the chosen utility function, depends only on relative prices. 
The inverse demand function and its derivative are

$$
p=u^{\prime}(X), \quad p^{\prime}(X)=u^{\prime \prime}(X)<0 .
$$

Production in the oligopolistic industry $X$ requires $c$ units of labor per unit of production and fixed costs of $F>0$ to set up a production plant. $F$ is assumed to be sufficiently high so that only one firm in each country is able to make positive profits. Hence there are two identical firms in our model, each located in one market. The two firms engage in Cournot quantity competition in each of the two markets. Exports of either firm to the other market cause trade costs of $s$ per unit of the good shipped. Following standard notation in the trade literature, $x$ describes the sales of the domestic firm in the home country and $y$ are the home country's imports from the foreign firm. Hence, aggregate consumption in the home market is $X=x+y$, and the inverse demand function is $p(x+y)$. Analogously, aggregate demand in the foreign market is $X^{*}=x^{*}+y^{*}$, where $x^{*}$ are the foreign firm's sales in the foreign country (i.e., its domestic market) and $y^{*}$ are the home firm's exports to the foreign market.

A commodity tax at rate $t$ is levied on the good produced in the oligopolistic industry $X$. In this section we focus on destination-based taxes, which fall on the consumption of good $X$. Note that the commodity tax considered here is selective, so that destination- and origin-based commodity taxes have different real effects. ${ }^{6}$ We model taxes to be specific rather than ad valorem. This is done for analytical simplicity, and in order to facilitate comparison with the modeling of specific tariffs in most of the trade literature. ${ }^{7}$

Under the destination principle, the home tax rate $t$ is levied on domestic and foreign goods sold in the home market ( $x$ and $y$ ), whereas the foreign tax rate $t^{*}$ applies to

\footnotetext{
${ }^{6} \mathrm{~A}$ long standing issue in international taxation is under which conditions destination- and origin-based commodity taxes can be equivalent. As emphasized by Lockwood, de Meza and Myles (1994), it is the selectivity of the commodity tax which causes equivalence to break down, not the presence of imperfect competition in product markets as such.

${ }^{7}$ It is well-known that in contrast to the competitive case, specific and ad valorem taxes or tariffs lead to different outcomes under imperfect competition. See Helpman and Krugman (1989, Ch. 4) for a comparison of specific vs. ad valorem tariffs in trade policy, and Delipalla and Keen (1992) for an analysis of this issue in the case of commodity taxation.
} 
all sales in the foreign country $\left(x^{*}\right.$ and $\left.y^{*}\right)$. The profit equations for the domestic and the foreign firm under the destination principle (superscript $D$ ) are

$$
\begin{aligned}
\Pi^{D} & =(p-c-t) x+\left(p^{*}-c-s-t^{*}\right) y^{*}-F \\
\Pi^{* D} & =\left(p^{*}-c-t^{*}\right) x^{*}+(p-c-s-t) y-F .
\end{aligned}
$$

An important assumption in this model is that firms perceive the two markets as segmented. Since marginal costs are assumed constant, the profit maximizing production decisions for the home and the foreign market can be completely separated (cf. Brander and Krugman, 1983). Furthermore, under the destination principle the domestic tax rate affects only the domestic market. We can thus focus on the optimal levels of $x$ and $y$ chosen by the domestic and the foreign firm, respectively, for sale in the home market. The analysis for the foreign market will be completely symmetric. The relevant first-order conditions are

$$
\begin{array}{r}
\Pi_{x}^{D}=p-c-t+p^{\prime} x=0, \\
\Pi_{y}^{* D}=p-c-s-t+p^{\prime} y=0,
\end{array}
$$

where subscript letters here and in the following denote partial derivatives. The firstorder conditions (6) and (7) give the two firms' reaction functions in output space. Note that (6) and (7) imply $x>y$ for $s>0$. Given that both firms face identical marginal costs and taxes under the destination principle, the domestic firm will have a larger market share in the home market since it does not incur trade costs.

The second-order conditions for a profit maximum are

$$
\Pi_{x x}=2 p^{\prime}+p^{\prime \prime} x<0, \quad \Pi_{y y}^{*}=2 p^{\prime}+p^{\prime \prime} y<0 .
$$

In the following, we impose the condition that the goods are strategic substitutes in the sense of Bulow, Geanakoplos and Klemperer (1985):

$$
\Pi_{x y}=p^{\prime}+p^{\prime \prime} x<0, \quad \Pi_{y x}^{*}=p^{\prime}+p^{\prime \prime} y<0 .
$$

Condition (9) guarantees that the reaction curves are negatively sloped so that the optimal reaction of a firm to output expansion of the rival firm is to reduce its own output. Comparing (9) with (8) shows that the assumption of strategic 
substitutability implies the sufficient second-order condition for a profit maximum. Finally, it follows from conditions (8) and (9) that the determinant of the Jacobian matrix of the two first-order conditions (6) and (7) must be positive:

$$
|J| \equiv \Pi_{x x} \Pi_{y y}^{*}-\Pi_{x y} \Pi_{y x}^{*}=3\left(p^{\prime}\right)^{2}+p^{\prime} p^{\prime \prime}(x+y)>0 .
$$

Condition (10) implies that each firm's own quantity choice has a larger effect on its marginal profits than the output choice of the competing firm, thus ensuring reasonable comparative statics results. To determine social welfare in the home country we use the budget constraint (2) to substitute out for $Z$ in the individual's utility function (1). Domestic welfare under the destination principle is then given by

$$
W^{D}=u(\cdot)-p(\cdot)(x+y)+\Pi^{D}+L+(x+y) t
$$

where $(\cdot)$ refers to the functional argument $(x+y)$. The first two terms in (11) give the consumer surplus in the oligopolistic industry, which is an exact welfare measure under the quasi-linear utility function assumed here. Maximizing (11) with respect to $t$ and using $u^{\prime}=p$ from (3) yields in a first step

$$
W_{t}^{D}=-p_{t}(\cdot)(x+y)+(x+y)+\left(x_{t}^{D}+y_{t}^{D}\right) t+\Pi_{t}^{D}=0 .
$$

To obtain the non-cooperative equilibrium tax rate under the destination principle, we differentiate the domestic firm's profits [eq. (4)] to get $^{8}$

$$
\Pi_{t}^{D}=\left(p_{t}(\cdot)-1\right) x+(p-c-t) x_{t}^{D} .
$$

Furthermore, $p_{t}(\cdot)=p^{\prime}(\cdot)\left(x_{t}^{D}+y_{t}^{D}\right)$. Finally we use $p^{\prime} x=p^{\prime} y-s$, which follows from the firms' first-order conditions (6) and (7). Rearranging and solving for the home government's nationally optimal tax rate $\hat{t}^{D}$ yields

$$
\hat{t}^{D}=\frac{1}{\left(x_{t}^{D}+y_{t}^{D}\right)}[\underbrace{p^{\prime} y\left(x_{t}^{D}+y_{t}^{D}\right)-s x_{t}^{D}}_{(\mathrm{I})(+,-)}+\underbrace{p^{\prime} y x_{t}^{D}-y}_{(\mathrm{II})(+)}] .
$$

\footnotetext{
${ }^{8}$ In the following we assume that the second-order conditions for a national welfare maximum are fulfilled under both tax principles, i.e., $W_{t t}<0$. Furthermore, we assume that a unique and symmetric Nash equilibrium exists in the present model.
} 
In equation (13) we have identified two main effects, which we label (I) efficiency effect and (II) rent shifting effect. Each of these effects can be further broken down into two parts. The efficiency effect consists of a term for the change in domestic consumption and a term for the efficiency costs of international trade. The rent shifting effect incorporates a profit shifting term in the home market and a tax exporting effect. ${ }^{9}$

To interpret and sign the different effects, we need to determine the general equilibrium responses of $x$ and $y$ to the change in the domestic tax rate $t$. These are derived in the appendix and are given by

$$
x_{t}^{D}=\frac{p^{\prime}+p^{\prime \prime}(y-x)}{|J|} \geq 0, \quad y_{t}^{D}=\frac{p^{\prime}+p^{\prime \prime}(x-y)}{|J|}<0, \quad x_{t}^{D}+y_{t}^{D}=\frac{2 p^{\prime}}{|J|}<0,
$$

where $|J|>0$ from (10). ${ }^{10}$

From (13) and (14) it follows that the efficiency effect (I) is ambiguous under the destination principle. The first (domestic) part of the efficiency effect is clearly negative and describes the familiar incentive to increase the suboptimally low consumption of the oligopolistically produced good $X$ by means of a subsidy. The second (traderelated) part of this effect is positive (negative) if $x_{t}^{D}>0\left(x_{t}^{D}<0\right)$. It reflects that an increase (reduction) in domestic production following a tax increase will reduce (increase) imports for any given level of domestic demand (controlled by the first effect), thereby saving (increasing) excess trade costs borne by domestic consumers. The rent shifting effect (II) is unambiguously positive under the destination principle. The first term depends again on the sign of $x_{t}^{D}$ as a positive response of domestic production to a tax increase implies that profits are shifted from the foreign to the

\footnotetext{
${ }^{9}$ The profit shifting term is also labeled terms of trade effect in parts of the literature.

${ }^{10}$ Note that the sign of $x_{t}^{D}$ is ambiguous, in general. Recalling that $x \geq y, x_{t}<0$ follows unambiguously if the inverse demand function is convex $\left(p^{\prime \prime}>0\right)$. In the opposite case of concave inverse demand $\left(p^{\prime \prime}<0\right)$, however, domestic production may rise in response to a domestic tax increase, if trade costs are high and $(y-x)$ is large in absolute value. Intuitively, $p^{\prime \prime}<0$ implies that demand is more elastic at low levels of output so that the tax increase will affect imports more than domestic production. In contrast, $y_{t}^{D}<0$ is always fulfilled from the assumption of strategic substitutability (9). Furthermore, aggregate consumption $x_{t}^{D}+y_{t}^{D}$ always falls in response to a tax increase, since $p^{\prime}<0$ from (3).
} 
domestic firm. The tax exporting effect in the second term is unambiguously positive, however, since the consumption tax falls partly on imports $(y)$ and thus shifts rents from the foreign firm to the domestic treasury. Furthermore, substituting $x_{t}^{D}$ from (14) and using (10) and (9), it can be shown that the positive tax exporting effect will dominate the profit shifting term, even if the latter is negative.

Having discussed the basic effects in detail, we can now substitute the results in (14) to simplify (13). Using (10), this yields after straightforward manipulations

$$
\hat{t}^{D}=-y p^{\prime \prime} x-\frac{s\left[p^{\prime}+p^{\prime \prime}(y-x)\right]}{2 p^{\prime}} .
$$

From (15) it is immediately seen that the balance between the competing effects depends critically on the curvature of the demand function. ${ }^{11}$ The results for noncooperative taxation under the destination principle can be summarized as follows: Proposition 1: (a) Under the destination principle, the nationally optimal tax rate is negative for all levels of trade costs, if the inverse demand function is convex $\left(p^{\prime \prime}>0\right)$. (b) If inverse demand is concave $\left(p^{\prime \prime}<0\right)$, then the optimal tax rate is positive at $s=0$ and it is positive at higher levels of $s$, iff $x_{t}^{D}>0$.

Proof: Part (a) of the Proposition follows immediately from substituting $p^{\prime \prime}>0$ into (15) and noting from $y \leq x$ that the second term in (15) is unambiguously negative in this case. For (b) we use $p^{\prime \prime}<0$ and either substitute $s=0$ or use the expression for $x_{t}^{D}$ in (14).

Intuitively, the curvature of the demand function determines how effective a subsidy is in raising domestic output. If the inverse demand function is convex $\left(p^{\prime \prime}>0\right)$ then the demand increase following a subsidy is large and the incentive to raise domestic consumption by means of a subsidy is strong. ${ }^{12}$ In contrast, if $p^{\prime \prime}<0$ then a tax increase causes only a moderate fall in domestic consumption and this effect is relatively weak. The nationally optimal tax will then be positive if trade costs are zero and the rent shifting term (II) is accordingly strong (because trade

\footnotetext{
${ }^{11}$ This is a well-known result from closed-economy models analyzing tax incidence and optimal taxation under conditions of imperfect competition. See, e.g., Myles (1995, Ch. 11).

${ }^{12}$ To see this analytically, note from (10) that $p^{\prime \prime}>0$ reduces the absolute value of the Jacobian determinant. As shown by the last term in (14), this leads to a larger fall in aggregate demand for good $X$ in response to a tax increase.
} 
levels and thus foreign profits in the domestic market are high). In addition, the destination-based tax may also turn positive at higher levels of $s$. The rent shifting effect will then be weak, but the efficiency effect turns positive if $x_{t}^{D}>0$ and a tax increase raises domestic production and reduces trade costs. Finally, note that in the special case of a linear inverse demand function $\left(p^{\prime \prime}=0\right)$ and zero trade costs, the counteracting incentives just offset each other and the non-cooperative consumption tax is zero.

These results can be compared to previous findings in the literature on strategic trade policy. In Brander and Spencer (1984, Propositions 1 and 2) the sign of the nationally optimal import tariff also depends on the curvature of demand. However, in their analysis the borderline case of a linear demand function involves a positive tariff at $s=0$, whereas this demand function implies a zero consumption tax in the present analysis. This difference is easily explained from the fact that the tariff affects only the imports of good $X$ and thus can be directly targeted at the rents that accrue to foreign producers in the home market. In contrast, a consumption tax simultaneously raises the price of domestically produced goods and thus implies a more severe underconsumption of good $X$ for any given level of rent shifting.

\section{Production taxes}

Under the origin principle, commodity taxes are levied in the country of production rather than in the country of final consumption. Hence the home country's tax rate $t$ now applies to the domestic sales of the home firm $(x)$ and to its exports to the foreign country $\left(y^{*}\right)$. Analogously, the foreign tax rate $\left(t^{*}\right)$ applies to the foreign firm's sales in each of the two countries $\left(x^{*}\right.$ and $\left.y\right)$. The profits of the domestic and the foreign firm under the origin principle (superscript $O$ ) are

$$
\begin{array}{r}
\Pi^{O}=(p-c-t) x+\left(p^{*}-c-s-t\right) y^{*}-F, \\
\Pi^{* O}=\left(p^{*}-c-t^{*}\right) x^{*}+\left(p-c-s-t^{*}\right) y-F .
\end{array}
$$

An important difference to the analysis in the previous section is that the domestic tax rate now affects both the home and the foreign market. Hence we need to determine the optimal levels of output that both firms produce for each market. 
The first-order conditions are

$$
\begin{array}{r}
\Pi_{x}^{O}=p-c-t+p^{\prime} x=0, \\
\Pi_{y}^{* O}=p-c-s-t^{*}+p^{\prime} y=0, \\
\Pi_{x^{*}}^{* O}=p^{*}-c-t^{*}+p^{* \prime} x^{*}=0, \\
\Pi_{y^{*}}^{O}=p^{*}-c-s-t+p^{* \prime} y^{*}=0 .
\end{array}
$$

Again the sufficient second-order conditions for a maximum will be implied by the assumption of strategic substitutability in both markets. These conditions are unchanged from eq. (9) above.

Welfare in the home country under the origin principle is given by

$$
W^{O}=u(\cdot)-p(\cdot)(x+y)+\Pi^{O}+L+\left(x+y^{*}\right) t
$$

where the tax base now includes the home country's exports of good $X$, rather than its imports. Using $u^{\prime}=p$ yields in a first step

$$
W_{t}^{O}=-p_{t}(\cdot)(x+y)+\left(x+y^{*}\right)+t\left(x_{t}^{O}+y_{t}^{* O}\right)+\Pi_{t}^{O}=0 .
$$

The effects of a tax increase on the domestic firm's profits are slightly more complicated than under the destination principle. Differentiating (16) gives

$$
\Pi_{t}^{O}=\left(p_{t}(\cdot)-1\right) x+(p-c-t) x_{t}^{O}+\left(p_{t}^{*}(\cdot)-1\right) y^{*}+\left(p^{*}-c-s-t\right) y_{t}^{* O} .
$$

Also, $p_{t}(\cdot)=p^{\prime}(\cdot)\left(x_{t}^{O}+y_{t}^{O}\right)$ and $p_{t}^{*}(\cdot)=p^{* \prime}(\cdot)\left(x_{t}^{* O}+y_{t}^{* O}\right)$. Finally, $p^{\prime} x=p^{\prime} y-s$ again follows from the firms' optimality conditions (18) and (19), and the fact that $t=t^{*}$ in the symmetric equilibrium. Solving for the home government's nationally optimal tax rate $\hat{t}^{O}$ and rearranging yields

$$
\hat{t}^{O}=\frac{1}{\left(x_{t}^{O}+y_{t}^{* O}\right)}[\underbrace{p^{\prime} y\left(x_{t}^{O}+y_{t}^{O}\right)-s x_{t}^{O}}_{(\mathrm{I})(-)}+\underbrace{p^{\prime} y x_{t}^{O}-p^{* \prime} y^{*} x_{t}^{* O}}_{(\mathrm{II})(-)}] .
$$

The efficiency effect (I) is analogous in structure to the optimal tax formula under the destination principle [eq. (13)]. The rent shifting effect (II) again incorporates a profit shifting term in the home market (the first term), but the tax exporting 
motive under the destination principle is now replaced by a profit shifting effect in the foreign market (the second term).

To sign these terms we use the following comparative static results, which are derived in the appendix:

$$
\begin{gathered}
x_{t}^{O}=\frac{2 p^{\prime}+p^{\prime \prime} y}{|J|}<0, \quad y_{t}^{O}=-\frac{\left(p^{\prime}+p^{\prime \prime} y\right)}{|J|}>0, \quad x_{t}^{O}+y_{t}^{O}=\frac{p^{\prime}}{|J|}<0, \\
x_{t}^{* O}=-\frac{\left(p^{* \prime}+p^{* \prime \prime} x^{*}\right)}{\left|J^{*}\right|}>0, \quad y_{t}^{* O}=\frac{2 p^{* \prime}+p^{* \prime \prime} x^{*}}{\left|J^{*}\right|}<0, \quad x_{t}^{* O}+y_{t}^{* O}=\frac{p^{* \prime}}{\left|J^{*}\right|}<0,
\end{gathered}
$$

where $|J|>0$ from (10), $\left|J^{*}\right|>0$ from symmetry and we have used the assumption of strategic substitutability [eq. (9)] to sign the terms. ${ }^{13}$

The efficiency effect (I) is unambiguously negative under the origin principle. The first term in (I) again captures the motive to correct for the domestic consumption inefficiency by means of a subsidy. Note, however, that this term will, ceteris paribus, be less strong than the corresponding effect under the destination principle because a production subsidy is only an imperfect instrument to raise domestic consumption in an open-economy setting. ${ }^{14}$ The second effect in (I) is also unambiguously negative under the origin principle since a domestic production tax will reduce domestic production and increase imports (cf. footnote 13), thus raising the excess trade costs borne by domestic consumers.

The rent shifting effect (II) is also unambiguously negative under the origin principle and thus has the opposite sign than under a consumption-based commodity tax. The first term in (II) shows that a positive production tax shifts profits in the home

\footnotetext{
${ }^{13}$ In contrast to the destination principle [eq.(14)], all output changes caused by a domestic tax increase are unambiguous under the origin principle. Since the tax falls only on domestic producers, it will lower the sales of the domestic firm in both the home market $(x)$ and the foreign market $\left(y^{*}\right)$. The contraction in supply induces a price rise which in turn leads the foreign firm - which is unaffected by the tax - to increase its supply in both markets ( $x^{*}$ and $y$, respectively). Aggregate consumption, however, must fall in both national markets.

${ }^{14}$ Algebraically, note from (24) that $x_{t}^{O}+y_{t}^{O}$ in the first term of (23) work in opposite directions, whereas $x_{t}^{O}+y_{t}^{* O}$ in the denominator of (23) have the same sign. Hence, the weight attached to this effect is lower than under the destination principle, where the corresponding terms simplify to unity [see eq. (13)].
} 
market towards the foreign firm, whereas the second term describes a parallel effect in the foreign market. Vice versa, a subsidy can be used to increase the profit share of the domestic firm in both national markets.

Using (24) in (23), the optimal tax formula can be simplified to

$$
\hat{t}^{O}=p^{\prime} y-\frac{s\left(2 p^{\prime}+p^{\prime \prime} y\right)}{4 p^{\prime}+p^{\prime \prime}(x+y)},
$$

and our results are summarized in

Proposition 2: Under the origin principle, the nationally optimal tax rate is negative for all levels of trade costs.

Proof: This follows directly from (25) and strategic substitutability [eq. (9)].

Proposition 2 shows that commodity taxes levied under the origin principle lead to results that resemble the case for strategic export subsidies, aimed at increasing the domestic firm's market share in a foreign market (Brander and Spencer, 1985). Together, our Propositions 1 and 2 thus encompass two of the main beggarthy-neighbor strategies analyzed in the literature on strategic trade policy: $(i)$ the incentive to shift profits from the foreign firm to the home treasury through an import tariff; and ( $i i)$ the incentive to shift profits from the foreign to the domestic firm through an export subsidy. Which of these two strategic incentives is at work in a commodity tax setting depends only on the international tax principle in operation.

Based on Propositions 1 and 2, we finally compare the non-cooperative tax rates under the destination and origin principles. It turns out that this comparison is less clear-cut than may appear at first sight. Our results are summarized in

Proposition 3: (a) The nationally optimal tax rate is higher under the destination principle, if the inverse demand function is concave $\left(p^{\prime \prime}<0\right)$ or if trade costs are zero. (b) The optimal tax rate is higher under the origin principle, if the inverse demand function is convex $\left(p^{\prime \prime}>0\right)$ and trade costs are sufficiently high.

Proof: See the Appendix.

Proposition 3 can be directly related to our earlier interpretation of eqs. (13) and (23), and in particular to the efficiency and the rent shifting effects. The comparison of Nash equilibrium tax rates under the two tax principles depends on two counteracting forces. On the one hand, the negative efficiency effect in the home 
market [the first term in (I)] is stronger under the destination principle, since the subsidy can be directly targeted at domestic consumption. On the other hand, the rent shifting effect (II) raises the optimal tax rate under the destination principle (sign of effect is positive), but lowers it under the origin principle (sign of effect is negative). Hence, it is intuitive that $\hat{t}^{D}>\hat{t}^{O}$ holds when trade costs are zero (or very low). When trade costs are high, $\hat{t}^{D}>\hat{t}^{O}$ will also hold if $p^{\prime \prime}<0$, since the incentive to subsidize domestic consumption is then relatively weak. However, when the domestic efficiency effect is strong $\left(p^{\prime \prime}>0\right)$ and the rent shifting terms are negligible (trade costs are high), then the failure of the origin principle to fully correct for imperfect competition implies that $\hat{t}^{D}<\hat{t}^{O}$.

\section{Welfare comparison of tax principles}

The analysis in the preceding sections has pointed out the different strategic incentives that exist for national tax policy under consumption- and production-based commodity taxation, leading to different equilibrium tax levels. The final objective of our paper is to compare the welfare levels that each country can obtain under the two alternative tax principles when tax rates are set non-cooperatively. The policy idea that underlies this analytical setting is that an international agreement on tax principles is far easier to reach than an agreement on tax rates. The relevance of this scenario is clearly demonstrated by the strong resistance of many member states of the European Union towards a further harmonization of value-added tax rates.

As a first step in this analysis, we derive the optimal tax formula that would result under aggregate welfare maximization and use it as a benchmark for the comparison of the two commodity tax regimes. In our symmetric setting, the optimal tax policy is equivalent to a coordinated tax policy under either the destination or the origin principle; hence, it does not matter whether we maximize joint utility under the first or the latter. There is, however, a clear expository advantage in determining the optimal tax rate under the destination principle. Under this tax scheme the national markets for good $X$ are independent and consumer surplus in each national market is affected only by the domestic commodity tax rate. Therefore, it is sufficient to consider the spillovers of domestic tax policy on the foreign firm's profits and thus 
choose the domestic tax rate so as to maximize the sum of domestic consumer surplus and the profits of both firms. By the symmetry of the model the foreign tax rate will be identical and the solution represents an aggregate global welfare optimum. Denoting all values that obtain under global welfare maximization by a tilde, the objective function is given by

$$
\tilde{W}=u(\cdot)-p(x+y)+(x+y) t+L+\Pi^{D}+\Pi^{* D},
$$

where the difference to (11) lies in the additional term for the profits of the foreign firm $\left(\Pi^{*}\right)$. Differentiating (26), using $u^{\prime}=p$ and $p_{t}(\cdot)=p^{\prime}(\cdot)\left(x_{t}^{D}+y_{t}^{D}\right)$ gives

$$
\tilde{W}_{t}=-p^{\prime}(\cdot)\left(x_{t}^{D}+y_{t}^{D}\right)(x+y)+(x+y)+\left(x_{t}^{D}+y_{t}^{D}\right) t+\Pi_{t}^{D}+\Pi_{t}^{* D}=0 .
$$

Using (4)-(5), we can solve for the optimal coordinated tax rate $\tilde{t}$

$$
\tilde{t}=\frac{1}{\left(x_{t}^{D}+y_{t}^{D}\right)}\left[p^{\prime} y\left(x_{t}^{D}+y_{t}^{D}\right)-s x_{t}^{D}\right]
$$

which can be further reduced, using (14):

$$
\tilde{t}=p^{\prime} y-\frac{s\left[p^{\prime}+p^{\prime \prime}(y-x)\right]}{2 p^{\prime}} .
$$

In general, the optimal coordinated tax rate balances the competing considerations to $(i)$ correct the domestic underconsumption of good $X$ in both countries and (ii) ensure an efficient level of trade. In the special case of zero trade costs, two-way trade yields no efficiency loss and only the domestic correction motive is operating. In this case the second term in (28) is zero and the optimal tax is unambiguously negative. When $s$ is increased, the market power of each national firm rises in its home market, increasing the need for a consumption subsidy. At the same time, however, two-way trade involves rising levels of wasteful trade costs. In the neighborhood of the autarky equilibrium, trade levels are unambiguously too high from a global welfare perspective (Brander and Krugman, 1983) and an optimal trade tax would be unambiguously positive. The sign of the optimal commodity tax is ambiguous, however, since a positive tax also aggravates the domestic underconsumption of $\operatorname{good} X$.

The next step is to compare (28) with the nationally optimal tax rate under the destination and the origin principle, respectively. We will consider two special cases 
- zero trade costs and trade costs that make it optimal to eliminate all trade - and show that the welfare ranking between the two tax principles is reversed when we move from low to high levels of $s$.

Since the second-order conditions for national welfare maximization are assumed to hold in the present analysis, and $W_{t}(t)$ is continuous and quasi-concave under both tax principles, it is possible to link tax rates and welfare levels in an unambiguous way. In particular, if one of the non-cooperative tax rates $\left(\hat{t}^{D}, \hat{t}^{O}\right)$ coincides with the optimal coordinated tax rate $\tilde{t}$ for a specific level of transport costs $s$, then the corresponding tax principle must (weakly) dominate the other in this point.

We first turn to the case where the level of trade costs is zero. As discussed above, the Pareto optimal tax rate is then unambiguously negative, as two-way trade causes no efficiency losses and tax policy serves the sole purpose of correcting the domestic distortions in the two national markets for good $X$. For this case we get:

Proposition 4: For zero trade costs $(s=0)$, the origin principle (strongly) welfare dominates the destination principle, that is $\left.\hat{W}^{D}\right|_{s=0}<\left.\hat{W}^{O}\right|_{s=0}$.

Proof: Setting $s=0$ in (15), (25) and (28) gives

$$
\hat{t}^{O}=\tilde{t}=p^{\prime} y \quad \text { and } \quad \hat{t}^{D}=-p^{\prime \prime} x y .
$$

The taxes $\hat{t}^{D}$ and $\hat{t}^{O}$ coincide if and only if $p^{\prime}=-p^{\prime \prime} x \Longleftrightarrow p^{\prime}+p^{\prime \prime} x=0$, which violates the assumption that the commodities are strategic substitutes [eq.(9)].

To understand this result, it is helpful to return to the detailed optimal tax formulae under the two tax principles, as developed in the preceding sections [eqs. (13) and (23)]. The efficiency term (I) is the same under the destination-based tax [eq. (13)] and the optimal tax [eq. (27)], if both are evaluated at $s=0$. This shows that the consumption-based tax in each country fully internalizes the optimal subsidy to correct for the domestic distortion. Hence, the non-cooperative tax rate under the destination principle will diverge from the optimal tax rate by the rent shifting effect (II). Since this effect is unambiguously positive under the destination principle, the nationally optimal tax rate $\hat{t}^{D}$ will always be 'too high' (i.e., subsidies are 'too low') from the perspective of global welfare maximization.

Under the origin principle [eq. (23)], the efficiency effect (I) falls short of the optimal subsidy [eq. (27)] at $s=0$, since the tax affects only that part of domestic 
consumption which is also domestically produced. However, the rent shifting effect (II) also works in the direction of a subsidy. In a symmetric model, and in the absence of trade costs, both firms share both markets equally and the strategic rent shifting effect just makes up for the incomplete incentive to subsidize domestic consumption. Hence, even though governments set tax rates non-cooperatively, the sum of all effects under the origin principle is just as large as in the aggregate welfare optimum.

Our Proposition 4 is closely related to Proposition 6 in Keen and Lahiri (1998). In the absence of trade costs, Keen and Lahiri show that non-cooperative tax setting under the origin principle is able to attain the first best solution if both countries are identical and trade costs are absent, whereas the same is not true under the destination principle. Our model reproduces this result for $s=0$, and it also offers an explanation that is related to the strategic rent shifting incentives known from the international trade literature. ${ }^{15}$ As we have argued above, it is the complete symmetry of the model in the absence of trade costs which ensures that the strategic rent shifting motive is an exact complement to the partial incentive to correct the domestic distortion. This, however, is no longer true when positive trade costs are introduced.

We now turn to the other limiting case where trade costs are so high that the optimal policy is to eliminate all trade. In the following we denote by $\tilde{s}$ the (minimal) level of trade costs for which the optimal tax $\tilde{t}$ implies $y=y^{*}=0$. The sign of $\tilde{t}$ is generally ambiguous at $\tilde{s}$, as the tax trades off the competing incentives to correct the domestic distortion on the one hand, and to cut off inefficient levels of trade on the other. It is important to emphasize that non-cooperative tax policy under the destination and origin principles need not eliminate trade at the same level of trade costs $\tilde{s}$; instead, this will be true if and only if the nationally optimal tax rate coincides with the optimal tax rate at $s=\tilde{s}$. The following proposition shows that

\footnotetext{
${ }^{15}$ Note also that with complete symmetry and zero trade costs the difference between the integrated market assumption in Keen and Lahiri (1998) and the segmented markets model assumed here is immaterial: even if firms are permitted to charge different prices in the home and the foreign market, they will not do so if trade costs are zero. This can be seen directly from eqs. (18) and (21) by setting $s=0$ and $x=y^{*}$.
} 
the destination principle always implies an efficient level of trade at $s=\tilde{s}$ whereas this is not generally true under the origin principle.

Proposition 5: At the level of trade costs that eliminates all trade under an optimal tax policy $(s=\tilde{s})$, the destination principle (weakly) welfare dominates the origin principle, that is $\left.\hat{W}^{D}\right|_{s=\tilde{s}} \geq\left.\hat{W}^{O}\right|_{s=\tilde{s}}$.

Proof: For each of $\hat{t}^{D}, \hat{t}^{O}$ and $\tilde{t}$ we assume that trade is eliminated by setting $y=0$ in (15), (25) and (28). This yields for the destination principle $\left.\hat{t}^{D}\right|_{y=0}=$ $\left.\left.\tilde{t}\right|_{y=0} \equiv \tilde{t}\right|_{s=\tilde{s}}$. Noting from (6)-(7) that $y$ is a monotonously falling function of $s$, it must then also be true that $\left.\hat{t}^{D}\right|_{s=\tilde{s}}=\left.\tilde{t}\right|_{s=\tilde{s}}$. In contrast, $\hat{t}^{O}$ and $\tilde{t}$ coincide for $y=0$ if and only if $2 p^{\prime} /\left(4 p^{\prime}+p^{\prime \prime} y\right)=\left(p^{\prime}-p^{\prime \prime} y\right) / 2 p^{\prime}$. The only demand specification which fulfills this condition and simultaneously meets the assumption of strategic substitutability [eq. (9)] is the linear inverse demand function $\left(p^{\prime \prime}=0\right)$. In all other cases $\left.\hat{t}^{O}\right|_{y=0} \neq\left.\tilde{t}\right|_{s=\tilde{s}}$, implying from the monotonicity of $y$ in $s$ [cf. eqs. (18)-(19)] that $\left.\hat{t}^{O}\right|_{s=\tilde{s}} \neq\left.\tilde{t}\right|_{s=\tilde{s}}$.

Intuitively, as trade costs approach prohibitively high levels the rent shifting effects (II) become less important under both tax principles and efficiency effects dominate. It is then seen from the comparison of eqs. (13) and (27) that non-cooperative taxation under the destination principle fully internalizes the optimal trade-off between an efficient level of domestic consumption and an efficient level of international trade. The reason is that, in each country, the destination-based tax can be targeted directly at the domestic underconsumption of good $X$, and it also incorporates all trade costs that must be borne by domestic consumers. In contrast, the origin-based tax deviates from the optimal tax in two respects: On the one hand, it neglects the import component of domestic demand, implying that the subsidy for domestic consumption is too low. On the other hand, it also neglects the trade costs borne by foreign consumers, leading to excessive subsidization of domestic exports. The net effect of these two deviations from the optimal tax rate at $s=\tilde{s}$ depends again on the curvature of the domestic demand function.

To see this in more detail, let us assume first that the inverse demand function is concave $\left(p^{\prime \prime}<0\right)$. In this case the efficiency effect is relatively weak so that the excessive subsidization of exports under the origin principle is the dominant effect. This conforms with Proposition 3(a), which shows that $\hat{t}^{D}>\hat{t}^{O}$ must hold at $s=\tilde{s}$, 
if inverse demand is concave. Since $\hat{t}^{D}$ is the globally efficient tax rate in this point, $\hat{t}^{O}$ must be 'too low' from a global welfare perspective. Furthermore, trade levels in the non-cooperative equilibrium are a monotonously falling function of national tax rates. Therefore, non-cooperative commodity taxation under the origin principle will still support positive levels of trade at $s=\tilde{s}$, and this trade is globally welfare reducing.

In the opposite case of a convex inverse demand function $\left(p^{\prime \prime}>0\right)$, the motive to subsidize domestic consumption is strong and the failure of the origin principle to fully internalize this effect leads to a production tax that is 'too high' from a global welfare perspective. This conforms with Proposition 3(b), given that the consumption-based tax rate is again optimal. Hence, under the origin principle trade is cut off at a level of trade costs below $\tilde{s}$, implying 'too little' trade in this range of $s$. For either $p^{\prime \prime}<0$ or $p^{\prime \prime}>0$ the origin principle thus induces autarky at a level of trade costs that differs from $\tilde{s}$, where trade should be eliminated from a global welfare perspective. The only exception arises in the 'intermediate' case of linear inverse demand $\left(p^{\prime \prime}=0\right)$. In this special case the deviations from the optimal tax rate are just offsetting, and non-cooperative taxation under the origin principle is Pareto efficient at $s=\tilde{s}{ }^{16}$

From Propositions 4 and 5 it is straightforward to develop our next, and final, proposition:

Proposition 6: As trade costs increase from $s=0$ to $s=\tilde{s}$, there is at least one critical level $s^{c}$ where the welfare ranking of the two tax principles is reversed, that is $\left.\hat{W}^{D}\right|_{s<s^{c}} \leq\left.\hat{W}^{O}\right|_{s<s^{c}}$ and $\left.\hat{W}^{D}\right|_{s>s^{c}} \geq\left.\hat{W}^{O}\right|_{s>s^{c}}$.

Proof: All optimal tax rates must be continuous functions of $s$, since they depend only on the first and second derivatives of the inverse demand function, which are continuously differentiable. Furthermore, from the assumption that the second-order conditions of the optimal tax problems are fulfilled under both tax principles, it follows that $W\left(\hat{t}^{D}\right)$ and $W\left(\hat{t}^{O}\right)$ are continuous and quasi-concave in $t$ for any level of $s$. Proposition 6 then follows directly from Propositions 4 and 5 .

The intuition for Proposition 6 follows immediately from our earlier discussion. As

\footnotetext{
${ }^{16} \mathrm{~A}$ detailed analysis of the linear inverse demand case is available from the authors upon request.
} 


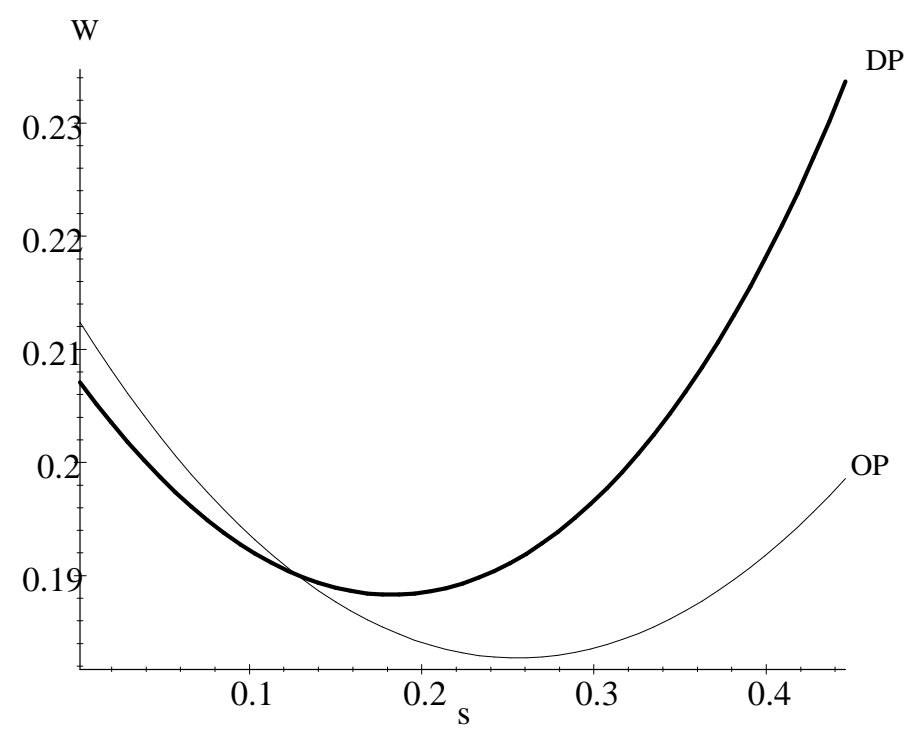

Fig. 1: Welfare as a function of $s$ with square root utility

Figure 1:

trade costs increase, the importance of the strategic rent shifting effects is reduced, and the non-cooperative tax rate under the destination principle approaches the optimal level. Thus, there must be a critical level of trade costs at which the advantage of the destination principle to optimally trade off domestic consumption efficiency and international trade efficiency dominates the welfare comparison of the two tax principles.

We illustrate our results in this section using the example of the square root utility function $u=\sqrt{X}$. For this utility function, Figure 1 plots welfare levels under both the destination and the origin principle as a function of trade costs. ${ }^{17}$

Note first that the welfare plots exhibit the U-shape typical for the reciprocal dumping model. At low levels of trade costs, trade is beneficial (i.e., the pro-competitive effect of trade dominates excess transportation costs) and increases in $s$ are welfare reducing. In contrast, trade is harmful at high levels of $s$ (i.e., the loss from excess trade costs exceeds the gains from increased consumption of good $X$ ) and a further rise in transport costs is welfare increasing (cf. Brander and Krugman 1983).

\footnotetext{
${ }^{17}$ The detailed computations for this case are available from the authors upon request.
} 
Turning to our specific analysis, Figure 1 shows that for low levels of $s$, a higher welfare level can be achieved with origin-based commodity taxation, whereas the destination principle dominates for high levels of $s$. The reversal of the welfare ranking occurs at $s=0.127 c$, i.e. $12.7 \%$ of the marginal production cost. This is just in between the different assumptions made by Markusen and Venables (1998) in their simulation model of trade and foreign direct investment (10\% and 15\%), and much lower than the trade cost estimates inferred from real-world trade patterns (see the quote from Norman, 1998, in the introduction). In short, the example of the square root utility function demonstrates that the reversal of the welfare ranking between the destination and origin principles is not merely a theoretical curiosity, but may well occur in an empirically relevant parameter range. ${ }^{18}$

Finally, we emphasize that the argument favoring the destination principle at high levels of $s$ does not depend on the symmetry assumption used in this model. As we have seen in section 2 , the destination principle allows to consider each market separately, if marginal production costs are constant and identical across firms. If trade costs are high, the nationally optimal tax rate in each country systematically incorporates the efficiency terms that result from aggregate welfare maximization, and this will remain true if countries differ with respect to population size or consumer preferences. In contrast, the superiority of the origin principle in the case of zero trade costs depends crucially on the symmetry assumption, which ensures that disparate effects (the incomplete domestic correction incentive and the rent shifting incentive) add up to the optimal tax rate.

\section{Conclusions}

Our aim in this paper was to exploit some of the insights from the literature on strategic trade policy in order to shed new light on the comparison between different international commodity tax principles under imperfect competition. For this purpose,

\footnotetext{
${ }^{18}$ Note that for $s>0.174 c$ the assumption of strategic substitutability is violated for the square root utility function. However, since the reversal of the welfare ranking between the origin and destination principles occurs within the permitted parameter range, this does not affect the main conclusions from the example.
} 
we have set up a symmetric two-country model with segmented national markets and trade costs in which both firms and governments behave non-cooperatively. In this framework, national tax policy faces a trade-off between the incentive to correct the domestic underconsumption of the good produced in the oligopolistic market, and the motive to shift profits from the foreign firm to the home country. We have seen that the latter effect, and hence the trade-off for national tax policy, depends qualitatively on the tax principle in operation. Rent shifting will tend to raise the optimal commodity tax rate if taxes are levied in the country of final consumption (destination principle), but lower it if the tax base is domestic production (origin principle).

Furthermore, our analysis has shown that the welfare comparison between the two tax principles depends crucially on the level of trade costs. If trade costs are zero, non-cooperative taxation under the origin principle is optimal, as an imperfect incentive to correct the domestic distortion in the goods market is just compensated by a strategic rent shifting effect. This is the same result that Keen and Lahiri (1998) have obtained in a model with integrated commodity markets. When trade costs are introduced, however, the strategic rent shifting incentives become less relevant while trade costs cause an element of pure waste that needs to be incorporated by an optimal tax policy. This tilts the welfare comparison in favor of the destination principle, which is able to trade off the conflicting goals of domestic consumption efficiency and international trade efficiency in a Pareto optimal way.

In addition, it should be emphasized that at least some of the simplifying features used in our analysis are likely to understate the arguments in favor of the destination principle. First, we have assumed the existence of lump-sum taxes. If distortive taxes have to be levied instead, then a subsidization policy will be less appealing. This tends to work against the origin principle, where subsidies are higher in most cases. ${ }^{19}$ Second, we have argued above that the symmetry of the trading countries is crucial for the welfare dominance of the origin principle when trade costs are zero, whereas the same restriction does not apply to the welfare dominance of the destination

\footnotetext{
${ }^{19}$ It has been shown by Keen and Lahiri (1998, Proposition 7) that with integrated national markets this argument reverses the welfare ranking in favor of the destination principle even in the absence of trade costs, if the shadow price of public revenues becomes sufficiently high.
} 
principle at high levels of trade costs. Hence, while a more general framework with asymmetric countries will greatly complicate the analysis - and perhaps make it intractable analytically - we expect that this extension generally strengthens the welfare case in favor of consumption-based commodity taxation.

In sum, it seems by no means clear that imperfect competition in product markets establishes a general case for production-based commodity taxation. Instead, welfare comparisons depend crucially on a number of central model parameters, and possibly also on the choice of the trade model itself. This opens up many new avenues for theoretical research, as well as empirical work assessing the quantitative magnitude of critical variables. However, if the new international trade literature is any guide, then it is unlikely that the emerging results based on models of imperfect competition are sufficiently robust to serve as a basis for actual tax policy. The conflicting implications derived from models of strategic trade policy have led many international trade theorists to return to the basic case for free trade as a 'rule of thumb' (see Krugman, 1987). In a similar way, we would argue that international tax specialists should stress the robust virtues of destination-based commodity taxes under conditions of perfect competition, even if these conditions are not generally met in practice. 


\section{Appendix}

Derivation of eqs. (14) and (24):

Destination Principle [eq. (14)]: To obtain the general equilibrium changes in the output levels $x$ and $y$ in response to a change in the domestic tax rate, we totally differentiate the firms' first-order conditions for profit maximization $\Pi_{x}(x, y, t)$ and $\Pi_{y}^{*}(x, y, t)[$ eqs. (6) and (7)]. This yields

$$
\begin{aligned}
& \Pi_{x x} d x+\Pi_{x y} d y+\Pi_{x t} d t=0 \\
& \Pi_{y x}^{*} d x+\Pi_{y y}^{*} d y+\Pi_{y t}^{*} d t=0 .
\end{aligned}
$$

Substituting the second-order derivatives given in eqs. (8)-(9) and $\Pi_{x t}=\Pi_{y t}^{*}=-1$ into (A.1) yields the simultaneous equation system

$$
\left[\begin{array}{cc}
2 p^{\prime}+p^{\prime \prime} x & p^{\prime}+p^{\prime \prime} x \\
p^{\prime}+p^{\prime \prime} y & 2 p^{\prime}+p^{\prime \prime} y
\end{array}\right]\left[\begin{array}{l}
d x \\
d y
\end{array}\right]=\left[\begin{array}{l}
1 \\
1
\end{array}\right] d t
$$

Applying Cramer's rule to (A.2) gives the expressions for $d x / d t \equiv x_{t}$ and $d y / d t \equiv y_{t}$ in eq. (14) of the main text.

Origin Principle [eq. (24)]: To obtain the effects of a domestic tax increase in the home market we totally differentiate the first-order conditions $\Pi_{x}(x, y, t)=0$ and $\Pi_{y}^{*}(x, y)=0$. This gives

$$
\left[\begin{array}{cc}
\Pi_{x x} & \Pi_{x y} \\
\Pi_{y x}^{*} & \Pi_{y y}^{*}
\end{array}\right]\left[\begin{array}{l}
d x \\
d y
\end{array}\right]=\left[\begin{array}{l}
1 \\
0
\end{array}\right] d t
$$

Similarly the effects of a domestic tax increase in the foreign market are obtained by totally differentiating $\Pi_{x^{*}}^{*}\left(x^{*}, y^{*}\right)=0$ and $\Pi_{y^{*}}\left(x^{*}, y^{*}, t\right)=0$. This yields

$$
\left[\begin{array}{ll}
\Pi_{x^{*} x^{*}}^{*} & \Pi_{x^{*} y^{*}}^{*} \\
\Pi_{y^{*} x^{*}} & \Pi_{y^{*} y^{*}}
\end{array}\right]\left[\begin{array}{l}
d x^{*} \\
d y^{*}
\end{array}\right]=\left[\begin{array}{l}
0 \\
1
\end{array}\right] d t
$$

Applying Cramer's rule to (A.3) and (A.4) gives

$$
x_{t}=\frac{\Pi_{y y}^{*}}{|J|}, \quad y_{t}=-\frac{\Pi_{y x}^{*}}{|J|}, \quad x_{t}^{*}=-\frac{\Pi_{x^{*} y^{*}}^{*}}{\left|J^{*}\right|}, \quad y_{t}^{*}=\frac{\Pi_{x^{*} x^{*}}^{*}}{\left|J^{*}\right|}
$$


where $|J|$ is given in (10) and $\left|J^{*}\right|=\Pi_{x^{*} x^{*}} \Pi_{y^{*} y^{*}}-\Pi_{x^{*} y^{*}} \Pi_{y^{*} x^{*}}$ is the analogous Jacobian for the foreign market.

The relevant second-order derivatives of the profit functions $\Pi$ and $\Pi^{*}$ are obtained from (18)-(21). Using the assumption of strategic substitutability, these can be signed as

$$
\begin{aligned}
\Pi_{y x}^{*} & =p^{\prime}+p^{\prime \prime} y<0, \quad \Pi_{y y}^{*}=2 p^{\prime}+p^{\prime \prime} y<0, \\
\Pi_{x^{*} y^{*}}^{*} & =p^{* \prime}+p^{* \prime \prime} x^{*}<0, \quad \Pi_{x^{*} x^{*}}^{*}=2 p^{* \prime}+p^{* \prime \prime} x^{*}<0 .
\end{aligned}
$$

Substituting (A.6) in (A.5) yields the results summarized in eq. (24) of the main text.

\section{Proof of Proposition 3:}

The proof is based on the first-order condition for national welfare maximization under the destination principle [eq. (12)]. Using $-p^{\prime} y+s=p-c-t$ from (7) and $p_{t}^{D}=p^{\prime}\left(x_{t}^{D}+y_{t}^{D}\right)$, this can be rewritten as

$$
W_{t}^{D}=-p^{\prime}\left(2 x_{t}+y_{t}\right) y+y+t\left(x_{t}+y_{t}\right)+s x_{t}
$$

We now evaluate this expression at the equilibrium tax rate under the origin principle. Since the second-order conditions of the government's maximization problem are assumed to hold under both tax principles, $W_{t}^{D}$ must be continuous and quasiconcave in $t$. We can then infer that $\hat{t}^{D}>\hat{t}^{O}$ when $\left.W_{t}^{D}\right|_{t=\hat{t}^{O}}>0$ and $\hat{t}^{D}<\hat{t}^{O}$ when $\left.W_{t}^{D}\right|_{t=\hat{t}^{O}}<0$. Setting $t$ equal to $\hat{t}^{O}$ in (23), using the comparative static results (14) and expanding by $|J|$ as given in (10) yields

$$
W_{t}^{D}\left(t=t^{*}=\hat{t}^{O}\right)=\frac{1}{|J|}\left[2 p^{\prime} y\left(p^{\prime}+p^{\prime \prime} x\right)+s p^{\prime \prime}(y-x) \frac{3 p^{\prime}+p^{\prime \prime}(x+y)}{4 p^{\prime}+p^{\prime \prime}(x+y)}\right] .
$$

From strategic substitutability [eq. (9)] the first term is unambiguously positive for $y>0$. The second term has the opposite sign as $p^{\prime \prime}$, since $y<x$ for $s>0$. Hence $\left.W_{t}^{D}\right|_{t=\hat{t}^{O}}>0$ if $s=0$ or if $p^{\prime \prime} \leq 0$. This demonstrates part (a) of the proposition. For part (b), note that a large level of $s$ implies that $y$ is small and hence the first positive term becomes small. Furthermore, the second term (which is negative if $p^{\prime \prime}>0$ ) increases with $s$ and decreases with $y$ in absolute terms. Hence, a sufficiently large $s$ exists such that the second term dominates the first for all levels of trade costs above this value, giving $\left.W_{t}^{D}\right|_{t=\hat{t}^{O}}<0$. 


\section{References}

Brander, J.A. (1981), Intra-industry trade in identical commodities. Journal of International Economics 11, 1-14.

Brander, J.A. and P.R. Krugman (1983), A 'reciprocal dumping' model of international trade. Journal of International Economics 15, 313-323.

Brander, J.A. and B. Spencer (1984), Tariff protection and imperfect competition, in: H. Kierzkowski (ed.), Monopolistic competition and international trade. Oxford University Press, 194-206.

Brander, J.A. and B. Spencer (1985), Export subsidies and international market share rivalry. Journal of International Economics 18, 83-100.

Bulow, J., J. Geanakoplos and P. Klemperer (1985), Multimarket oligopoly: Strategic substitutes and complements. Journal of Political Economy 93, 488-511.

Cnossen, S. (1998), Global trends and issues in value added taxation. International Tax and Public Finance 5, 399-428.

Delipalla, S. and M. Keen (1992), The comparison between ad valorem and specific taxation under imperfect competition. Journal of Public Economics 49, 351367.

Eaton, J. and G.M. Grossman (1986), Optimal trade policy under oligopoly. Quarterly Journal of Economics 101, 383-406.

Haufler, A. and I. Wooton (1999), Country size and tax competition for foreign direct investment. Journal of Public Economics 71, 121-139.

Helpman, E. and P. Krugman (1989), Trade policy and market structure. MIT Press, Cambridge (Mass.).

Hoel, M., 1997, Environmental policy with endogenous plant locations. Scandinavian Journal of Economics 99, 241-259.

Janeba, E. (1998), Tax competition in imperfectly competitive markets. Journal of International Economics 44, 134-153. 
Kanbur, R. and M. Keen (1993), Jeux sans frontières: Tax competition and tax coordination when countries differ in size. American Economic Review 83, 877-892.

Keen, M. and S. Lahiri (1998), The comparison between destination and origin principles under imperfect competition. Journal of International Economics 45, 323-350.

Keen, M. and S. Smith (1996), The future of value-added tax in the European Union. Economic Policy 23, 375-420.

Krugman, P. (1979), Increasing returns, monopolistic competition, and international trade. Journal of International Economics 9, 469-479.

Krugman, P. (1980), Scale economies, product differentiation, and the pattern of trade. American Economic Review 70, 950-959.

Krugman, P. (1987), Is free trade passé? Economic Perspectives 1, 131-144.

Krugman, P. and A. Venables (1995), Globalization and the inequality of nations. Quarterly Journal of Economics 110, 857-880.

Lockwood, B. (1993), Commodity tax competition under destination and origin principles. Journal of Public Economics 53, 141-162.

Lockwood, B. (1998), Tax competition and tax co-ordination under destination and origin principles: A synthesis. Mimeo, University of Warwick.

Lockwood, B., D. de Meza and G. Myles (1994), When are origin and destination regimes equivalent? International Tax and Public Finance 1, 5-24.

Markusen, J.R., E.R. Morey and N.D. Olewiler (1995), Competition in regional environmental policies when plant locations are endogenous. Journal of Public Economics 56, 55-77.

Markusen, J.R. and A.J. Venables (1998), Multinational firms and the new trade theory. Journal of International Economics 46, 183-203. 
Mikesell, J.L. (1997), The American retail sales tax: Considerations on their structure, operations, and potential as foundations for a Federal sales tax. National Tax Journal 50, 149-165.

Mintz, J. and H. Tulkens (1986), Commodity tax competition between member states of a federation: Equilibrium and efficiency. Journal of Public Economics 29, 133-172.

Myles, G.D. (1995), Public Economics. Cambridge University Press.

Norman, V. (1998), A small open economy perspective on international competition policy, in: E. Hope and P. Maelang (eds.), Competition and trade policies: Coherence or conflict. Routledge, London and New York, 57-64.

OECD (1999), Revenue statistics. Paris.

Osmundsen, P., K. Hagen and G. Schjelderup (1998), Internationally mobile firms and tax policy. Journal of International Economics 45, 97-113.

Rauscher, M. (1995), Environmental regulation and the location of polluting industries. International Tax and Public Finance 2, 229-244.

Wilson, J.D. (1999), Theories of tax competition. National Tax Journal 52, 269-304. 